\title{
PLANTÃO PSICOLÓGICO: UMA PRÁTICA CLÍNICA DA CONTEMPORANEIDADE ${ }^{1}$
}

\author{
Psychological Duty: a Contemporary Clinical Practice \\ Turno Psicológico: una Práctica Clínica de la Contemporaneidad
}

Melina SÉfora SouZa Rebouças

Elza Dutra

\begin{abstract}
Resumo: O objetivo desse artigo é refletir sobre plantão psicológico enquanto uma prática clínica da contemporaneidade, entendendo este tipo de intervenção como sendo mais adequada a uma nova postura da psicologia clínica, em que o psicólogo deverá estar comprometido com a escuta e o acolhimento do outro onde quer que este esteja. Visando apresentar um panorama da atualidade e de suas principais demandas foi realizada uma revisão bibliográfica acerca dos desdobramentos da psicologia clínica, bem como do sofrimento humano, trazendo uma reflexão ética e política e a defesa de práticas mais condizentes com a realidade atual. Desse modo, podemos dizer que o plantão psicológico constitui-se como uma prática clínica da contemporaneidade, na medida em que ela promove uma abertura para o novo, o diferente e oferece um espaço de escuta a alguém que apresenta uma demanda psíquica, um sofrimento, oferece um momento no qual esse sujeito que sofre se sinta verdadeiramente ouvido na sua dor, favorecendo para que este possa ressignificar o seu estar no mundo.
\end{abstract}

Palavras-chave: Plantão Psicológico; Clínica Fenomenológica; Contemporaneidade; Escuta Clínica; Ética.

\begin{abstract}
This paper aims to reflect on psychological duty as a contemporary clinical practice, understanding that this type of intervention would be more appropriate in a new conduct of clinical psychology, in which the psychologist should be committed to listening and sheltering the other person wherever they are. With the attempt of presenting a panorama of today's situation and its main demands, we elaborated a literature review about clinical psychology and human suffering, reflecting political and ethical perspectives and also defending practices that are more consistent with the current reality. Thereby, we can say that psychological duty is a contemporary clinical practice, given that it promotes changes and new possibilities for the ones with psychic demand or any kind of suffering, as it offers them an open space for being listened and understood in their pain, encouraging them to construct a new meaning to their existence in the world.
\end{abstract}

Keywords: Psychological Duty; Phenomenological Clinic; Contemporaneity; Clinic Listening; Ethics.

Resumen: El objetivo de este artículo es reflexionar a cerca del turno psicológico, una práctica clínica psicológica contemporánea. Esta práctica es percibida como el tipo de intervención más apropiado para una nueva postura de la psicología clínica, en la cual el psicólogo debe de comprometerse a escuchar y acoger a las personas sea donde sea. Con el propósito de ofrecer un panorama general de la actualidad y de sus principales demandas, elaboramos una revisión de literatura a cerca del desarrollo de la psicología clínica y del sufrimiento humano, buscando una reflexión ética y política, además de defender las prácticas más coherentes con la realidad actual. Así pues, se puede decir que el turno psicológico es una práctica clínica contemporánea, ya que promueve una apertura al nuevo y al diferente, ofreciendo a los que tienen una demanda psicológica o presentan algún tipo de sufrimiento, un espacio de escucha y acogimiento de su dolor, ayudándoles a construir un nuevo sentido a su existencia en el mundo.

Palabras-clave: Turno psicológico; Clínica Fenomenológica; Contemporaneidad; Escucha Clínica; Ética.

\section{Introdução}

A psicologia, nos moldes tradicionais, norteada por uma noção de sujeito descontextualizado social e historicamente e cujas práticas se restringiam ao atendimento em consultórios privados, não mais se adequa à sociedade de hoje. O homem contemporâneo tem de-

\footnotetext{
Esse trabalho é resultado da monografia do Curso de Especialização em Psicologia Clínica na Abordagem Fenomenológico-Existencial da Universidade Federal do Rio Grande do Norte (UFRN), orientada pela segunda autora.
}

mandado novas formas de inserção do psicólogo; na verdade, uma nova postura, um novo olhar sobre ele. Portanto, necessitando de um profissional mais comprometido com o contexto social. A definição de clínica, em função disso, não pode mais se restringir ao local e à clientela que atende; trata-se, sobretudo, de uma postura diante do ser humano e sua realidade social, exigindo, portanto, do psicólogo, uma capacidade reflexiva continuamente exercitada em relação à própria prática, da qual se origine um posicionamento ético e político (Dutra, 2004). 
A psicologia clínica passa agora a ser tratada não como uma área de atuação, mas como atitude, como ethos, de acordo com o pensamento de alguns autores, entre os quais (Dutra, 2004; Figueiredo, 1996; Safra, 2004 e Sá, 2007). Nesse sentido, o psicólogo clínico contemporâneo deverá estar comprometido com a escuta e o acolhimento do outro onde quer este esteja. O que significa compreender esse outro a partir da experiência e dos significados que ele atribui ao mundo, levando em consideração o contexto no qual está inserido, considerando-o como um ser-no-mundo e, portanto, constituído por este, ao mesmo tempo em que o constitui.

Dentro dessa perspectiva contemporânea, tem-se falado numa nova modalidade clínica que veio não substituir a psicoterapia, mas se constituir numa alternativa a esta; na verdade, trata-se de uma prática que se adequa às demandas atuais, e nomeada por Mosqueira, Morato e Noguchi (2006) como uma prática de atenção psicológica. Neste trabalho, discutiremos a respeito do Plantão Psicológico, entendendo este como uma modalidade de atendimento clínico-psicológico de tipo emergencial, aberto à comunidade (Cury, 1999), cuja função é proporcionar uma escuta e um acolhimento à pessoa no momento de crise. Lembrando que tal proposta não tem como finalidade a resolução ou o aprofundamento da "problemática” da pessoa, mas um momento de compreensão do seu sofrimento.

O plantão psicológico, segundo Oliveira (2005), acontece como um espaço que favorece a experiência, tanto do cliente como do plantonista, no qual o psicólogo se apresenta como alguém disposto, presente e disponível e não apenas como detentor do conhecimento técnico. E isto seria um estar junto, um inclinar-se na direção sofrimento, deixando-se afetar, e a partir daí compreender o outro.

O presente trabalho justifica-se pela pouca bibliografia sobre o assunto, o que revela uma incipiente produção científica. Fala-se muito em práticas emergentes, mas não há um posicionamento crítico em relação a estas e o que ocorre, na maioria das vezes, é uma transposição do modelo clínico tradicional para outros setores. Outro fator é a grande procura pelos serviços psicológicos que tem gerado longas listas de espera no setor público, fruto dessa não-adequação da psicologia tradicional às novas demandas. Nem todo mundo que procura um serviço psicológico quer ou precisa de psicoterapia; talvez o que eles precisem seja um contato verdadeiro e acolhedor naquele momento, no qual as pessoas se sintam realmente ouvidas e à vontade para colocar o que quer que lhes estejam afligindo, e assim, poderem ampliar o seu nível de consciência e de clareza sobre o que estão vivenciando. Nesse sentido, o plantão psicológico já pode ser considerado, por si só, terapêutico.

Tendo em vista a proposta de discorrer e refletir sobre plantão psicológico como uma prática clínica da contemporaneidade, faz-se necessário discutirmos sobre os des- dobramentos da psicologia clínica, bem como do sofrimento humano na tentativa de apresentar um panorama da atualidade e de suas principais demandas, trazendo uma reflexão ética e política sobre essa ação e a defesa de práticas mais condizentes com essa realidade da clinica psicológica na atualidade.

\section{Desdobramentos da Psicologia Clínica}

A psicologia clínica foi instituída tradicionalmente como um método, e para se instaurar como ciência ela precisava se adequar ao modelo metafísico da época, caracterizado pela crença em uma verdade única e imutável. Modelo este dominado pela herança médica do diagnóstico e da cura com fins de previsão e controle das massas, servindo, então, aos interesses da classe dominante. Segundo Feres-Carneiro e Lo Bianco (2003), a psicologia clínica ficou tradicionalmente conhecida pela prática do psicodiagnóstico e da psicoterapia de cunho psicanalítico. Estas eram realizadas em consultórios particulares e destinadas à população de classe média e alta, cuja ênfase se dava nos aspectos psicológicos e psicopatológicos do indivíduo. Tais práticas dominaram o cenário da psicologia clínica durante um longo tempo, mas novas demandas foram surgindo e fazendo com que os profissionais repensassem essas práticas, além de servir como um berço fértil para que surgissem novas perspectivas sobre o homem que não fossem baseadas somente em relações determinísticas.

O que acontece é que o paradigma científico moderno passa a ser questionado frente à impossibilidade da neutralidade e objetividade do pesquisador e pesquisado e da busca de uma verdade que seja absoluta e inquestionável, o que acaba por trazer grandes transformações no meio científico e, consequentemente, na própria psicologia. Segundo Roehe (2005),

A atitude científica clássica ignora a complexidade ontológica do homem. Não reconhece o papel do ser humano na constituição da realidade e, portanto, não considera adequadamente a presença do cientista numa investigação. Em resumo: não reconhece o ser do homem, pois o trata como uma coisa diante de outra coisa. Por isso, erra. (...) Cria-se uma situação absurda: o pesquisador atua para conhecer, negando sua própria presença cognoscente (p. 157).

Frente a essas problematizações, a subjetividade passa agora a ser colocada como condição de conhecimento e compreensão dos fenômenos humanos, abrindo espaço para que se estruture um novo paradigma que leve em consideração a especificidade de cada conhecimento (Morato, 1999).

Compartilhando também desse pensamento, Figueiredo (2004) nos fala que a gestação do espaço psi- 
cológico se dá em meio ao projeto epistemológico da modernidade. Projeto esse que, como vimos, busca a produção e validação do conhecimento através da cisão mente e corpo, na tentativa de construir um sujeito epistêmico pleno, senhor de si e fiador de todas as certezas. Segundo ele, é justamente a partir dessa cisão que a psicologia se constitui na medida em que ela passa a "cuidar" de tudo que é excluído por esse método. Em outras palavras, a psicologia se abre como o espaço do interditado, da subjetividade.

Nesse momento, como nos fala Carvalho (1992, citado por Morato 1999), "certezas começam a ser feridas, gerando crises de sentido e de ética no seio hegemônico, antes tão fortemente estabelecido" (p. 65). O mundo contemporâneo demanda novas formas de conhecimento, busca um paradigma não mais baseado numa verdade universal, mas em múltiplas verdades, constituídas a partir da singularidade do ser humano, do seu contexto e de sua história. Nesse sentido também fala Leitão e Nicolaci-daCosta (2003) - baseando-se nas idéias de Lyotard - de que o mundo pós-moderno é compreendido como fragmentado, complexo e imprevisível e, dessa forma, descrevê-lo de uma maneira unificada torna-se impossível, já que este passa a ser constituído de múltiplas narrativas.

Tais transformações no mundo e no meio científico vão exigir da psicologia clínica um novo pensamento conceitual em que não cabe mais a importação de modelos teóricos. O modelo individualista que ditava o modus operandi da psicologia clínica e o corpo teórico dado a priori não mais satisfaz. Seu compromisso agora passa a ser com o social, e essa articulação faz com que a ética e não o referencial teórico - seja o principal norteador de sua prática. Nesse sentido, seguir uma nova perspectiva de clínica implica expressar um posicionamento ético e político (Dutra, 2004).

No entanto, faz-se de extrema importância ressaltar que, de acordo com Ferreira Neto (2004), esse novo "fazer clínico" ou as ditas "práticas emergentes” não são garantias de que nelas estejam implicadas uma dimensão ético-política.

Essa questão também é discutida por Yamamoto, Trindade e Oliveira (2002) ao afirmarem que essas novas formas de inserção caracterizam-se por uma formação acadêmica precária, condições de prática adversas e que não se diferenciam do fazer clínico tradicional. O que nos leva a pensar que a grande questão não diz respeito à novidade das práticas que saíram dos consultórios para hospitais e postos de saúde, mas à sua adequação. Dessa forma, Paulon (2004) afirma que, "trata-se muito mais de questionarmos as novas formas com que o sofrimento psíquico se apresenta, os sintomas sociais contemporâneos se impõem e os modos pelos quais os fazeres "psi" estão estruturados para atendê-los" (p. 264). Daí a necessidade de nós psicólogos pensarmos sobre o contexto social e suas forças subjacentes, de modo a poder adequar a prática às condições vigentes de uma for- ma crítica. Somente a partir dessas problematizações é que as mudanças podem ocorrer.

Segundo Figueiredo (2004), a definição de psicologia clínica não pode se restringir ao local, à clientela, a uma prática, a um campo de intervenção ou a uma área de conhecimento. Ele afirma que apesar de existir as especificidades de cada um desses lugares, a clínica não pode ser reduzida a estes: ela é muito mais ampla.

O que podemos observar é que a dificuldade de definição é inerente ao campo psicológico devido a sua dispersão teórica e prática, por isso, ao tentar delimitá-la em classificações reducionistas fracassa. "A clínica, portanto, é o espaço privilegiado destes cruzamentos. Espaço no qual torna-se impossível recortar as práticas psi, ou lhes possibilitar localizações definitivas" (Silva, 2001). Assim, o que vai definir a psicologia clínica é a sua ética, entendendo esta como um assento, uma morada, isto é, como um compromisso de escuta e acolhimento do ser humano onde quer que este esteja.

Safra (2004) compreende o Ethos como "as condições fundamentais que possibilita o ser humano morar, estar e constituir-se como um habitante no mundo humano" (p. 115). Nessa acepção, a psicologia clínica é uma atitude, um modo de se relacionar com o outro, um cuidado que possibilitará ao homem sentir-se acolhido numa morada, ressaltando que esse homem deve ser compreendido a partir de sua singularidade, isto é, a partir da experiência e dos significados que este atribui ao mundo. Não cabe mais aprisioná-lo em teorias, mas entendê-lo através da revelação dos seus modos de ser. O psicólogo clínico, então, é um profissional do encontro na medida em que esteja disponível para abrir-se à alteridade, entendendo-a como algo desconhecido e inusitado (Figueiredo, 1993).

A psicologia clínica contemporânea nos coloca diante de situações imprevisíveis que põem em questão nossas teorias e práticas. Como o nosso compromisso agora é com a ética, devemos nos dispor a sermos eternos aprendizes na medida em que o desconhecido bate à porta de nossos consultórios e nos ensina os caminhos que irão nos levar à revelação da condição humana. Nesse sentido, não é mais possível mover a clínica em torno de uma técnica, pois esta, ao se caracterizar pelo cuidado, passa a ser essencialmente ética e essa ética é clínica (Safra, 2004).

O cuidado irá proporcionar um sentir-se em casa, a partir do qual se criam condições para o encontro com a alteridade. Sendo assim, o psicólogo clínico, ao se deparar com múltiplas alteridades, como diz Figueiredo (1993), gera a multiplicidade oficial da psicologia. Multiplicidade esta sem a qual não existiríamos e que acaba sendo minimizada quando o psicólogo se fecha em uma única prática ou teoria. O ideal no mundo contemporâneo seria proporcionar o trânsito entre esses saberes, lembrando, como dito anteriormente, que o que define a clínica é a sua relação com o outro através do ethos do cuidado e, portanto, tais saberes deveriam se adequar a esta definição e não ao contrário. Figueiredo (1993) corrobora isso: 
(...) a atividade profissional do psicólogo requer uma incorporação dos saberes psicológicos às suas habilidades práticas de tal forma que mesmo o conhecimento explícito e expresso como teoria só funciona enquanto conhecimento tácito; o conhecimento tácito do psicólogo é o seu saber de ofício, no qual as teorias estão impregnadas pela experiência pessoal e as estão impregnando numa mescla indissociável. (...). O resultado é que a adesão explícita e assumida a uma 'escola' diz muito pouco da efetiva atuação profissional; na verdade creio que quanto mais conta a experiência, quanto mais tempo no exercício da profissão, mais as variáveis pessoais vão pesando na definição das práticas e das crenças dos psicólogos (p. 91).

As experiências do psicólogo, portanto, é que o conduzirão aos mais diversos caminhos, como diz Morato (1999), "É no contexto, portanto, das experiências da clínica psicológica, enquanto uma prática, que a teoria começa a engendrar-se" (p. 69).

A clínica comprometida com a emergência de novos sentidos e com a singularidade tem a obrigação de ousar, arriscar, inventar, enfim, de estar sempre em movimento e em permanente construção. Assim, não pode estar circunscrita em um único saber ou ser compreendida a partir de uma única lógica. A contemporaneidade tem demandado da clínica uma postura multi e transdisciplinar diferentemente do que ocorria na modernidade. Poderíamos dizer que essa é a "verdadeira" clínica, não mais utilizada para adjetivar a psicologia, mas sinônimo desta.

\subsection{Histórico do Plantão Psicológico}

O plantão psicológico surge como uma modalidade de atendimento proposta pelo Serviço de Aconselhamento Psicológico (SAP) do Instituto de Psicologia da Universidade de São Paulo (IPUSP) em 1969, tendo como coordenadora a professora Rachel Lea Rosenberg, cujo objetivo inicial era oferecer um atendimento diferenciado à clientela que procurava o serviço, constituindo-se como uma alternativa às longas filas de espera.

A implantação do SAP aconteceu num momento em que se lutava pelo reconhecimento da profissão do psicólogo no Brasil e também com o aparecimento da Psicologia Humanista no país, proposta pelo psicólogo americano Carl Rogers, também chamada de "terceira força", por se opor às correntes psicológicas até então vigentes, como a psicanálise e o behaviorismo. Tal fato serviu de impulso aos estudiosos e profissionais que buscavam alternativas às teorias e práticas tradicionais, como afirma Rosenberg (1987), “(...) deu-nos o senso de identidade sócio-profissional, incentivou nossos estudos, ajudou a superar diferenças individuais entre nós e levou-nos a acreditar, definitivamente, num novo modelo clínico de Psicologia, que ultrapassava o consultório para chegar à comunidade." (p. 3).

O plantão psicológico baseia-se no modelo de aconselhamento psicológico proposto por Carl Rogers, o qual, inicialmente, esteve atrelado ao exame da personalidade por meio dos testes psicológicos ${ }^{2}$. No entanto, Rogers, a partir de sua prática, começa a questionar esse modelo de aconselhamento e propõe uma mudança de perspectiva, passando a dar importância ao cliente e não ao problema, à relação e não ao instrumental de avaliação, ao processo ao invés do resultado. Morato (1999) diz que Rogers não se deteve somente na técnica e voltou-se para as possibilidades da relação de ajuda e,

(...) caminhou no sentido de não se restringir unicamente a prática clínica tradicional, ou seja, da psicoterapia, e seguiu o caminho do aconselhamento psicológico. Não se fechou em uma prática clínica. Ouvindo as demandas sociais e reformulando este campo em função das demandas, foi possível dirigirse para outros contextos que, também demandavam ajuda: escolas/educação, grupos, conflitos sociais, empresas. Amalgamando essas experiências, passou a repensar como a origem de tensões, conflitos e crises dos homens e pessoas encontram-se nas diversas situações do relacionamento humano. Ou seja, da condição humana no mundo com os outros” (p. 82).

Dessa forma, o aconselhamento psicológico se configura pela abertura do conselheiro para acolher qualquer demanda que se apresente. A idéia é receber o cliente e facilitar para que este se posicione diante de seu sofrimento e decida se o atendimento será um aconselhamento, uma orientação ou uma psicoterapia. O conselheiro ao acolher o cliente pode, junto com este, explorar não só a queixa, mas outras possibilidades diante desta. $\mathrm{O}$ aconselhamento psicológico, então, constitui-se pela disponibilidade e flexibilidade em propor alternativas de ajuda.

O SAP foi idealizado pelo Dr. Oswaldo de Barros Santos, em função da necessidade de oferecer aos alunos da disciplina de Aconselhamento Psicológico uma oportunidade de estágio e atendimento psicológico à clientela. Desde o final da década de 60 tem passado por muitos desafios e reformulações, mantendo-se, segundo Morato (1999), "atenta para a formação do psicólogo, buscando esclarecer condições de ajuda mais pertinentes à demanda da comunidade que procura o Serviço, partindo da compreensão da complexidade da experiência humana." (p. 31).

Segundo Eisenlohr (1999), nos anos 80 o SAP passou por um período de crise devido a algumas contradições existentes entre o que era pensado sobre o serviço e o que acontecia na prática, tornando-se urgente a necessidade de

\footnotetext{
O aconselhamento psicológico teve sua origem baseada no modelo metafísico abordado no primeiro capitulo.
} 
se refletir e aprofundar sobre essas questões. O que aconteceu nessa época foi a impossibilidade de acompanhar a demanda que surgiu, gerando uma longa fila de espera, o que acabou por inviabilizar a real proposta do plantão de um atendimento imediato. Concomitantemente a essa situação também surgiu um grave problema de infra-estrutura devido à interdição do local onde aconteciam os atendimentos e a equipe viu-se obrigada a suspender as atividades do plantão por dois semestres.

Passada a crise, já na década de 90, e apesar da crescente expansão dos serviços oferecidos pelo SAP este mantém suas características iniciais de atendimento psicológico gratuito à população, tendo como porta de entrada o plantão psicológico e seus possíveis encaminhamentos para a psicoterapia ou outros serviços de saúde, como também um espaço para a formação profissional do psicólogo e para a discussão de projetos e pesquisas no sentido de aprofundar e promover melhorias nos serviços.

O SAP tem sido referência até hoje a outros profissionais que inseriram o plantão psicológico em outras instituições tais como escolas, hospitais, empresas, varas de famílias, delegacias e consultórios particulares, fruto da constante necessidade de repensar as práticas tradicionais e oferecer alternativas mais adequadas às demandas do mundo contemporâneo.

A primeira sistematização pública a respeito do plantão psicológico ocorreu em 1987 pelo professor Dr. Miguel Mahfoud, sendo o primeiro a falar sobre o plantão como uma modalidade clínica e sobre a sua inserção em diferentes contextos. Segundo Mahfoud (1987) "A expressão plantão está associada a certo tipo de serviço, exercido por profissionais que se mantêm à disposição de quaisquer pessoas que deles necessitem, em períodos de tempo previamente determinados e ininterruptos.” (p. 75).

Tal definição nos remete à origem da palavra Plantão, que vem do francês planton, cujo significado é um soldado a serviço que permanece fixo ou em pé em um lugar, sempre em estado de alerta. Daí a palavra também designar os serviços noturnos em hospitais, fábricas, jornais, etc. Um outro sentido que vem do verbo plantar originado do latim plantare significa introduzir um vegetal na terra para criar raízes, isto é, ficar parado, estacionado. Trazendo para a idéia do plantão psicológico podemos entender como um estar disponível diante de um organismo vivo que cresce e precisa ser cuidado (Tassinari, 1999).

Nesse sentido o trabalho do plantonista é o de ajudar o cliente a ter uma visão mais ampliada de si e do mundo estando disponível para compreender e acolher a experiência deste, no momento de sua expressão, isto é, frente àquela problemática que gerou o pedido de ajuda. (Mahfoud, 1987).

O plantão psicológico, de acordo com Mahfoud (1987), surge da necessidade de oferecer atendimento psicológico a uma parcela da população que, na maioria das vezes, no momento de sua urgência não é atendida devido à es- cassez dos recursos públicos para a saúde que acaba por priorizar os casos "mais graves", tendo como conseqüência uma especialização das demandas. Diante disso, podemos fazer um questionamento: Será possível nos dias de hoje saber o que é "grave" e o que é "banal"? Acredito que não, pois cair nisso é um desrespeito a singularidade do ser humano e, independente da demanda que chegue, o que importa é a necessidade de ser ouvido.

Assim, a questão que se coloca é o de oferecer um espaço de atendimento a essas pessoas que estão à margem da sociedade, qualquer que seja a sua demanda, na medida em que o foco é definido pelo próprio cliente e não pela especialização do profissional. A proposta do plantão é aceitar manter-se junto com o cliente no momento presente, na problemática que emerge, promovendo uma melhor avaliação dos recursos disponíveis, ampliando, assim, seu leque de possibilidades. (Mahfoud, 1987). É a partir dessa idéia mais sistemática do plantão psicológico que se torna possível a sua inserção em diferentes contextos e/ou instituições.

\section{O Sofrimento Humano numa Perspectiva Ontoló- gica}

Depois de falarmos dos desdobramentos da psicologia clínica faz-se necessário refletirmos, brevemente, sobre o sofrimento e o sofrente: Quem é este homem? Quais os seus sentidos? O que o leva a sofrer? Quais as suas demandas para a psicologia clínica? Com esse intuito, proponho, neste tópico, trazer algumas considerações do sofrimento humano a partir de uma perspectiva ontológica.

De acordo com Koogan e Houaiss (1999), sofrimento quer dizer uma dor física ou moral, padecimento, amargura, desgraça, desastre. No senso-comum o sofrimento está relacionado à dor, agonia, aflição e amargura, muitas vezes associado a um acontecimento marcante (injustiças, doenças ou perdas).

Segundo Barus-Michel (2001), etimologicamente o sofrimento significa carregar, suportar ou tolerar uma dor. Podemos observar nessas definições que o sofrimento está sempre atrelado a uma dor, como nos fala Sasdelli e Miranda (2001), "É comum fazermos referência à dor e ao sofrimento como um só fenômeno. De fato, os limites que separam os dois são tênues" (p. 103).

No entanto, é importante ressaltar que o sofrimento é anterior à dor por fazer parte da complexidade da experiência humana em seus diversos aspectos, pois mesmo que não exista dor, existirá um sofrimento, mas acontece que esse sofrimento na maioria das vezes emerge como dor e insiste em permanecer como sintoma orgânico. Devido a isso, é dada mais importância à dor, esquecendo que esta "surge como uma forma emergente dos conflitos da pessoa e não, como se costuma pensar, que ela é a causa primeira dos conflitos" (Sasdelli \& Miranda, 2001, p. 102). Nesse sentido, o sofrimento é aqui entendido como 
inerente à condição humana, pois a dor pode ser evitada, mas o sofrimento não (Sasdelli \& Miranda, 2001).

Segundo Dantas e Tobler (2003), o sofrimento esteve sempre presente na história da humanidade sob diferentes formas e terminologias. Tal fato nos leva a reconhecer a sua relatividade e singularidade, pois cada indivíduo, cultura e período histórico vão ter sua própria manifestação do sofrimento. Então, devido a sua dimensão subjetiva, o sofrimento não pode ser somente definido a partir dos acontecimentos que o desencadeiam. De acordo com Brant e Minayo-Gomez (2004),

O sofrimento depende da significação que assume no tempo e no espaço, bem como no corpo que ele toca (...). O homem sofre porque passa a perceber a sua finitude; o que faz do sofrimento uma dimensão não apenas psicológica, mas, sobretudo existencial (p. 215).

Nesse sentido o sofrimento faz parte da constituição do ser humano; na verdade, é a sua condição. Segundo Safra (2004), o homem desde o nascimento cruza com o mistério da existência que só é possível através da presença do outro. A partir disso ele conhece as condições necessárias para a instalação de si no mundo com os outros, o que podemos chamar do próprio acontecer humano. No entanto, o excesso de claridade ou de escuridão - quando o homem sabe demais a respeito de si e do mundo ou quando nada sabe - impede esse acontecer humano e o homem sofre. E esse sofrimento advém da própria condição humana, da sua ontologia, e não apenas de uma dor moral, física ou psíquica.

A partir de Heidegger podemos compreender a ontologia como o estudo do "ser enquanto ser", isto é, a procura das origens genuínas que permitem a tudo manifestar-se e presentar-se. Dessa forma, ontológico refere-se àquilo que possibilita as várias formas de algo tornar-se presente. Heidegger parte da vida cotidiana, dos fenômenos ônticos para estudar o ser e seus aspectos ontológicos. E ôntico é tudo aquilo que é conhecido e entendido de imediato, refere-se às experiências do cotidiano, aos acontecimentos do dia a dia. O ontológico, então, é o fundamento, é o que possibilita os acontecimentos ônticos (Spanoudis, 1981).

Partindo dessa conceituação poderíamos entender o sofrimento como sendo ôntico pelo fato deste fazer parte das experiências do cotidiano, já que o homem sofre de diversas formas em seu dia a dia. No entanto, neste capítulo, daremos ênfase à dimensão ontológica do sofrimento, entendendo este como constitutivo, fundante, isto é, inerente à condição humana e que, de acordo com Safra (2004), apesar de alcançar, no cotidiano, o registro psíquico, físico e moral, não tem sua origem nestes, mas acontecem no registro ontológico.

Diante disso, faz-se necessário que o ser humano permaneça sempre no entre, isto é, entre o dito e o não-dito, entre o encontro e a solidão, entre o claro e o escuro, enfim, não caia nos exageros, como diz Brant e MinayoGomez (2004): “(...) o sofrimento está relacionado com um saber acerca da existência que não se sabe todo (...)” (p. 215). Assim, compreender esse ocultamento e desocultamento do homem evitaria a agonia do impensável e a agonia do totalmente pensável, pois são sofrimentos enlouquecedores (Safra, 2004).

Nessa mesma perspectiva, Almeida (1999), baseandose na ontologia de Heidegger, afirma que o homem é um ser lançado no mundo - o ser-aí (Dasein) - e isso significa dizer que ao homem está entregue à responsabilidade de ser num mundo em que não escolheu, que já está dado e do qual nada se sabe, estando, portanto, vulnerável às contingências deste. Assim, está sob sua tutela escolher suas possibilidades de ser, que pode acontecer no modo da impropriedade ou da propriedade, ou seja, de uma forma inautêntica ou autêntica. Na primeira o homem encontra-se absorvido no mundo e afasta-se de si mesmo e seu poder-ser próprio está vedado; a segunda acontece quando o homem se dá conta de sua impropriedade e passa a viver uma angústia, sendo esta a única possibilidade de abrir-se para si mesmo e ir em busca de seu poder-ser mais próprio.

Dessa forma, poderíamos dizer que o sofrimento "saudável” seria aquele advindo da angústia de ser lançado num mundo inóspito que não consegue nos abrigar e nos acolher. No entanto, essa experiência de desamparo e desabrigo que queremos superar é, na verdade, a condição de liberdade do próprio homem, pois a angústia gerada por essa experiência abre o homem para si mesmo, para a sua singularidade (Critelli, 1996). A angústia promove um conhecimento a respeito de si que advém do próprio fato do homem ser lançado em meio à existência na busca das condições que permitam seu alojamento no mundo com os outros (Safra, 2004). Como nos fala Almeida (1999), a angústia tira o homem de sua absorção no mundo na medida em que esta faz com que o homem se afaste do mundo e não encontre mais a ilusória familiaridade e proteção de anteriormente e estando sozinho no mundo passa a agir de acordo com suas próprias convicções. Essa capacidade mobilizadora da angústia pode ser vista nesse trecho de Clarice Lispector:

Uma das coisas que aprendi é que se deve viver apesar de. Apesar de, se deve comer. Apesar de, se deve amar. Apesar de, se deve morrer. Inclusive muitas vezes é o próprio ‘apesar de' que nos empurra para a frente. Foi o 'apesar de' que me deu uma angústia que insatisfeita, foi a criadora de minha própria vida (1998, p. 26).

Diante disso, para que possamos permitir o acontecer humano, isto é, para que o homem possa ser si mesmo (ser no modo da propriedade) é preciso compreendermos a condição ontológica do sofrimento humano e as formas com que este se apresenta na contemporaneidade. O so- 
frimento é aqui entendido como uma ruptura do ethos ${ }^{3}$ humano, ruptura essa que provoca um sentimento de não pertencimento ao mundo humano devido à falta de espaço para a alteridade e singularidade.

No mundo contemporâneo poderíamos entender essa ruptura como a alienação que a sociedade, pautada na ética do consumo, provoca por meio da globalização, no qual este "conspira" para o mesmo, não havendo lugar para o diferente, o singular (Safra, 2004). Dantas e Tobler (2003) comentam que a sociedade de consumo oferece um modelo de felicidade baseada em função dos objetos que um indivíduo possui. O que acaba por gerar problemas na esfera da individualidade, já que ao invés de obter algo que quero ou preciso, obtenho aquilo que todos têm e acreditam ser o objeto de felicidade. Tal fato provoca um profundo vazio existencial que o faz querer ainda mais consumir tais objetos, criando a falsa ilusão de que a "cura" desse vazio pode ser comprada.

Outra ruptura provocada pela contemporaneidade é a tentativa de explicar e revelar o ser humano em sua totalidade por meio de teorias. Um exemplo disso atualmente é a psiquiatrização do sofrimento, em que qualquer tristeza ou frustração é diagnosticada como depressão (Dantas \& Tobler, 2003). Safra (2004) também corrobora com essa idéia ao afirmar que na atualidade temos um sofrimento que é descrito como sofrimento do totalmente pensado, isto é, algumas concepções da psicologia e da pedagogia levam a um tudo dizer sobre o ser humano, no qual este já se encontra classificado em categorias ou quadros psicopatológicos. Parece haver uma necessidade de nomear, explicar e curar todo e qualquer sofrimento, como se as pessoas tivessem que ser felizes.

Ferreira Neto (2004), baseando-se nas idéias de Foucault, sugere que o parâmetro ético do mundo contemporâneo é a eficiência. Segundo ele, em tempos de globalização o que impera é a otimização do desempenho através da lógica do gerenciamento. Por exemplo, os pais hoje não educam mais seus filhos, mas os gerenciam, pois desde cedo os aprontam para a vida profissional colocando-os em aulas de informática e inglês, na tentativa de torná-los mais preparados para o mercado de trabalho e, portanto, mais eficientes. No entanto, essa corrida pela eficiência tem provocado as atuais formas de adoecimento que chegam à clínica, como o transtorno obsessivo-compulsivo (TOC), a depressão e a anorexia. Fazendo um paralelo, poderíamos dizer que o TOC, através das manias características poderia ser pensado como uma tentativa de acompanhar o ritmo desenfreado da sociedade de consumo, como se estas tornassem o homem mais próximo dessa eficiência almejada. No caso da depressão ocorre o contrário, o homem não consegue acompanhar esse ritmo e cai num profundo vazio existencial e fica paralisado diante da vida. Já a anorexia poderia representar um

O sentido de ethos é o mesmo referido no primeiro capítulo. exemplo da distorção que a busca pela eficiência provoca, na medida em que a sociedade estabelece padrões a serem seguidos.

De uma forma geral, compreender a condição ontológica do ser humano é reconhecê-lo em sua singularidade e saber que este não pode ser totalmente explicado ou revelado. Como afirma Critelli (1996), todo saber a respeito do homem sempre será relativo e provisório, já que é impossível para este alcançar qualquer fixidez pelo fato de estar em contínuo vir-a-ser. O mundo contemporâneo vai demandar da clínica o restabelecimento do ethos e este só será possível através da compreensão dessa dimensão ontológica do homem.

O mundo contemporâneo, como vimos, provoca rupturas no ser humano que o leva a um tipo de sofrimento sem entorno ${ }^{4}$, a uma vida sem sentido e a um completo alheamento de si, e viver dessa forma muitas vezes é pior que a própria morte. "Na atualidade inúmeras pessoas sonham com a morte como maneira de escapar do Nada e como gesto desesperado de anseio por acontecer" (Safra, 2004, p. 59). Nesse caso o homem vive suspenso em um estado de agonia, no qual este clama por transformar essa experiência em algo que lhe dê sentido ou que possa vir a ser um sofrimento (Safra, 2004).

O que tem acontecido é que a contemporaneidade não tem permitido ao homem sofrer, tentando de todas as formas eliminar ou abafar o sofrimento, mas esse "controle" é ilusório pelo fato deste fazer parte da constituição ontológica do ser humano e ser a condição de abertura para o nosso acontecer, isto é, nosso poder ser próprios. Na verdade, "Sofrer implica em devir, em destinar o vivido" (Safra, 2004, p. 70).

\section{Plantão Psicológico: uma Prática Clínica da Con- temporaneidade}

Depois desse breve percurso na história da psicologia clínica e das reflexões acerca do mundo contemporâneo, podemos, agora, colocar essas discussões em prática. Proponho, então, neste tópico, discorrer sobre o Plantão Psicológico entendendo este como uma prática condizente com a atual realidade.

A clínica contemporânea, como falamos anteriormente, está baseada numa ética e não mais numa técnica, e nesse sentido o psicólogo não está preso a um local ou campo de atuação, ele pode estar em diversos lugares. Assim, o plantão psicológico surge como uma alternativa de prestação de serviços condizente com essa nova postura da clínica em que o psicólogo passa a estar comprometido com a escuta e sensível às demandas que chegam, mesmo que esse encontro seja único. Porém, vale ressaltar que essa proposta não se trata de uma psicoterapia alternativa e nem visa substituir a esta. Na verda-

\footnotetext{
4 Sofrimento enlouquecedor.
} 
de, o que tentamos defender é o plantão como uma prática da clínica contemporânea e que é possível ampliá-la para diversos campos da prática profissional. Exemplo disso são os atuais serviços em que o psicólogo está inserido como o PSF (Programa de Saúde da Família), o CAPS (Centro de Atenção Psicossocial) e o CRAS (Centro de Referência da Assistência Social) que têm por objetivo acolher e dar a assistência necessária à população no momento de sua procura.

Vimos que a contemporaneidade tem demandado da clínica uma postura de ousadia, de transformação, de inquietação e de permanente construção. O plantão psicológico, assim, vai exigir do profissional uma disponibilidade para se deparar com o inesperado e, diante disso, buscar alternativas. O plantão psicológico, de acordo com Morato (1999) caracteriza-se como um espaço de acolhimento e escuta no momento em que a pessoa procura ajuda, tentando propiciar a elaboração e ressignificação do seu sofrimento, utilizando seus próprios recursos e, na medida do possível, os recursos que a instituição dispõe ou indo buscá-los fora desta. Compartilhando dessa idéia, Tassinari (1999) define o plantão psicológico como:

(...) um tipo de atendimento psicológico, que se completa em si mesmo, realizado em uma ou mais consultas sem duração pré-determinada, objetivando receber qualquer pessoa no momento exato de sua necessidade para ajudá-la a compreender melhor sua emergência e, se necessário, encaminhá-la a outros serviços. Tanto o tempo da consulta, quanto os retornos dependem de decisões conjuntas (plantonista/cliente) no decorrer do atendimento. É exercido por psicólogos que ficam à disposição das pessoas que procuram espontaneamente o Serviço em local, dias e horários pré-estabelecidos, podendo ser criado em diversos locais e instituições. Em cada ambiente, precisará, criar estratégias específicas, desde sua divulgação (processo de sensibilização à comunidade) até sua relação com a própria instituição/local (p. 44).

Dessa forma, o profissional será um facilitador ao ajudar o cliente a ter uma visão mais clara de si mesmo e da problemática que o trouxe, utilizando sempre o poder pessoal do cliente, ajudando, assim, na promoção de saúde e estimulando a prevenção.

Falamos também do compromisso da clínica contemporânea com a dimensão política e social, em função qual o profissional precisa repensar sua prática de acordo com a realidade atual e com o meio em que está inserido. $\mathrm{O}$ plantão psicológico, então, como nos fala Morato (1999), "redimensiona a aprendizagem e a compreensão do papel do psicólogo e seu campo de atuação (...)" (p. 35), além de proporcionar ao psicólogo entrar em contato com as necessidades de uma comunidade exercendo um papel de agente transformador e multiplicador social.
Diante disso, podemos observar como a proposta do plantão psicológico se adequa a essa nova postura da clínica em todos os seus aspectos, tendo a ética como principal norteador, entendendo esta como uma atitude, como um cuidado e como uma abertura para o outro, estando o profissional disposto a fazer uma psicologia sem nome, mas que deixe emergir o mundo do outro, como afirma Ancona-Lopez (1996):

(...) quando o cliente vem à procura de um psicólogo, ele quer ser atendido em suas necessidades, pouco importando sob que nome este atendimento se efetue. $\mathrm{Na}$ prática, no entanto, o que acontece com freqüência é que, por nomear sua prática, o psicólogo deixa de fazer sua parte, postergando sua intervenção e empobrecendo um encontro rico de possibilidades (p.115).

Nesse sentido, o psicólogo, no plantão psicológico, independente de onde esteja ou do nome que recebe, estará ali para atender a pessoa, focalizando a sua atenção nesta e não no problema. Dessa forma, a eficácia do plantão psicológico não está relacionada à resolução da problemática em questão, já que a prioridade não é a queixa, mas o mundo de significados daquela pessoa, e o papel do psicólogo é ajudá-la a refletir e buscar novas maneiras para lidar com as suas dificuldades. É importante lembrar que o plantão não é solução para tudo, existem muitos limites, a maioria devido à grande desigualdade social e à defasagem dos serviços públicos (Cury, 1999). No entanto, a proposta do plantão mostra-se como um alcance dos serviços psicológicos a uma população que talvez nunca tivesse acesso, servindo como espaço de acolhimento e de informações, auxiliando as pessoas a ter uma maior autonomia emocional, bem como um esclarecimento acerca de sua realidade social e de seus direitos enquanto cidadão.

\section{Considerações Finais}

A contemporaneidade, como vimos, tem demandando da Psicologia Clínica uma nova postura e um novo olhar diante do homem. E para isso, a psicologia rompe com o modelo metafísico baseado no instrumental técnico e em verdades absolutas e inquestionáveis, indo de encontro a uma clínica pautada na ética.

E pautar-se na ética é levar em consideração a singularidade humana, abrindo-se ao encontro do outro e oferecendo-lhe uma morada, isto é, um espaço para que este se sinta verdadeiramente acolhido. O Plantão Psicológico seria, portanto, um desses espaços, estando o profissional disponível para se deparar com o não-planejado, deixando-se, como coloca Ferreira (2006), afetar pela singularidade de cada existência e de cada encontro.

As características do mundo contemporâneo levam o homem a perder sua morada, seu espaço no mundo, sen- 
tindo-se, desse modo, perdido e completamente alienado se si, fato que provoca as atuais formas de adoecimento anteriormente comentadas no capitulo II. O que falta a este homem é ser ouvido, é ser compreendido em sua singularidade e essa escuta não precisa ocorrer somente nos consultórios. O psicólogo pode estar aberto para essa alteridade onde quer que o ser humano se encontre, como nos fala Ferreira (2006): "o Plantão Psicológico delineia-se como um serviço a serviço de quem solicita atenção psicológica, extrapolando a concepção de clínica enquanto dimensão física ou prática de consultório, expandindo-se e legitimando-se em diferentes contextos (...)” (p. 20).

Podemos dizer que o plantão psicológico constituise como uma prática clínica da contemporaneidade, na medida em que ela promove uma abertura para o novo, o diferente e oferece um espaço de escuta a alguém que apresenta uma demanda psíquica, um sofrimento, oferece um momento no qual esse sujeito que sofre se sinta verdadeiramente ouvido na sua dor. E ouvir, segundo Amatuzzi (2001), é se permitir entrar verdadeiramente no universo de significados do outro para, dessa forma, auxiliá-lo na construção e/ou reconstrução dos sentidos que realmente dizem respeito à sua existência. É um mergulho no universo interior da pessoa que fala, sem a interferência de julgamentos e valores, a partir do qual se abrem possibilidades dela mesma se ouvir.

Nesse sentido, o plantão, ao oferecer esse espaço, promove o restabelecimento do ethos que foi perdido, devolvendo ao homem seu lugar no mundo. As pessoas não necessariamente precisam de uma psicoterapia para se sentir bem, muitas precisam apenas dessa atitude, desse novo olhar, dessa "mão estendida" para que elas possam ser quem realmente são, para que possam se enxergar como seres únicos, para que possam ter aquilo que o mundo atual não permite que tenham, mesmo que seja por um breve momento. A proposta do plantão é justamente criar condições para que o indivíduo possa por si só encontrar seus caminhos, mas esta trilha muitas vezes é tortuosa e em alguns momentos o homem precisará desse espaço para se fortalecer e posteriormente continuar. Assim, o plantão estará à disposição sempre que alguém precisar.

\section{Referências}

Amatuzzi, M. (2001). Por uma Psicologia Humana. São Paulo: Alínea.

Ancona-Lopez, S. (1996). A porta de entrada: da entrevista de triagem à consulta psicológica. Tese de Doutorado. Pontifícia Universidade Católica de São Paulo. São Paulo, SP.

Almeida, F. (1999). Aconselhamento Psicológico numa Visão Fenomenológico-Existencial: Cuidar de Ser. Em H. T. P. Morato (Org.), Aconselhamento Psicológico Centrado na Pessoa (p. 45-59). São Paulo: Casa do Psicólogo.
Barus-Michel, J. (2001). Sofrimentos, trajetos, recursos. Dimensões psicossociais do sofrimento humano. Em T. M. J. A. Vaisberg \& F. F. Ambrósio (Orgs.), Trajetos do Sofrimento: Rupturas e (re) Criações de Sentido (p. 17-40). Cadernos Ser e Fazer, Instituto de Psicologia da Universidade de São Paulo.

Brant, L. C. \& Minayo-Gomez, C. (2004). A transformação do sofrimento em adoecimento: do nascimento da clínica à psicodinâmica do trabalho. Ciência e Saúde Coletiva, 9 (1), 213-223.

Critelli, D. M. (1996). A respeito da fenomenologia. Em D. M. Critelli, Analítica do sentido: uma aproximação e interpretação do real de orientação fenomenológica (p. 11-24). São Paulo: Educ/Brasiliense.

Cury, V. E. (1999). Plantão psicológico em Clínica Escola. Em M. Mahfoud (Org.), Plantão Psicológico: novos desafios (p. 115-116). São Paulo: Companhia Ilimitada.

Dantas, M. A. \& Tobler, V. L. (2003). O sofrimento psicológico é a pedra angular sobre o qual repousa a cultura de consumo. Acesso em 20 de junho de 2007 de http://www.psicologia. com.pt/artigos/ver_artigo.php?codigo=A0175.

Dutra, E. (2004). Considerações sobre as significações da psicologia clínica na contemporaneidade, Estudos de Psicologia, Natal, 9 (2), 381-387.

Eisenlohr, M. G. V. (1999). Serviço de Aconselhamento Psicológico do IPUSP: breve histórico de sua criação e mudanças ocorridas na década de 90. Em H. T. P. Morato (Org.), Aconselhamento Psicológico Centrado na Pessoa: novos desafios (p. 135-143). São Paulo: Casa do Psicólogo.

Feres-Carneiro, T. \& Lo Bianco, A. C. (2003). Psicologia Clínica: uma identidade em permanente construção. Em O. H. Yamamoto \& V. V. Gouveia (Orgs.), Construindo a psicologia brasileira: desafios da ciência e prática psicológica (p. 99-119). São Paulo: Casa do Psicólogo.

Ferreira, R. S. (2006). Possíveis implicações da experiência com plantão psicológico para a ação do psicólogo clínico. Dissertação de Mestrado, Universidade Católica de Pernambuco.

Ferreira Neto, J. L. (2004). A formação em nossa atualidade. Em J. L. Ferreira Neto, A formação do psicólogo: clínica, social, mercado (p. 162-186). São Paulo: Escuta.

Figueiredo, L. C. M. (1993). Sob o signo da multiplicidade, Cadernos de Subjetividade, São Paulo, 1, 89-95.

Figueiredo, L. C. M. (2004). Revisitando as psicologias: Da epistemologia à ética das práticas e discursos psicológicos. Petrópolis, Rio de Janeiro: Vozes.

Koogan A., \& A. Houaiss (1999). Enciclopédia e dicionário ilustrado Koogan / Houaiss. Rio de Janeiro: Seifer.

Leitão, C. F. \& Nicolaci-da-Costa, A. M. (2003). A Psicologia no novo contexto mundial. PUC: Rio de Janeiro. Estudos de Psicologia, 8 (3), 421-430.

Lispector, C. (1998). Uma aprendizagem ou o livro dos prazeres. Rio de Janeiro: Rocco. 
Mahfoud, M. (1987). A Vivência de um Desafio: plantão psicológico. Em R. L. Rosenberg (Org.), Aconselhamento Psicológico Centrado na Pessoa (p. 75-83). São Paulo: EPU.

Mahfoud, M. (Org.) (1999). Plantão Psicológico: novos horizontes. São Paulo: Companhia Ilimitada.

Morato, H. T. P. (1999). Aconselhamento psicológico: uma passagem para a transdisciplinariedade. Em H. T. P. Morato (Org.), Aconselhamento psicológico centrado na pessoa: novos desafios (p. 61-89). São Paulo: Casa do Psicólogo.

Mosqueira, S. M., Morato, H. T. P. \& Noguchi, N. F. C. (2006). Atenção psicológica: de plantão a acompanhamento na FEBEM/SP [texto completo]. Em Laboratório de Estudos e Prática em Psicologia Fenomenológica Existencial (Org.), Anais da I Jornada Plantão Psicológico em Aconselhamento Psicológico (p.194-203). São Paulo: Autor.

Oliveira, R. G. (2005). Uma experiência de plantão psicológico à polícia militar do Estado de São Paulo: reflexões sobre sofrimento e demanda. Dissertação de mestrado, Universidade de São Paulo, SP.

Paulon, S.M. (2004). Clínica Ampliada: Que(m) demanda ampliações? Em T.G Fonseca \& S. Engelman (Orgs.), Corpo, Arte e Clínica (p. 259-274). Porto Alegre, Ed. UFRGS.

Roehe, M. V. (2005). Uma abordagem fenomenológico-existencial para a questão do conhecimento em psicologia. Estudos de Psicologia, 11 (2), 153-158.

Rosenberg, R. L. (Org.) (1987). Aconselhamento Psicológico Centrado na Pessoa. São Paulo: EPU.

Sá, R. N. (2007). A noção fenomenológica de existência e as práticas psicológicas clínicas. [Texto completo]. Em VII Simpósio Nacional de Práticas Psicológicas em Instituição - Fronteiras da Ação Psicológica entre educação e saúde, Anais do VII Simpósio Nacional de Práticas Psicológicas em Instituição - Fronteiras da Ação Psicológica entre educação e saúde (p.1-5). São Paulo: Liber Livros Editora.

Safra, G. (2004). A po-ética na clínica contemporânea. Aparecida, SP: Idéias e Letras.

Sasdelli, E. N. \& Miranda, E. M. F. (2001). Ser: o sentido da dor na urgência e na emergência. Em V. A. Angerami-Camon (Org.), Psicossomática e Psicologia da dor (p. 93-110). São Paulo: Pioneira.

Silva, É. R. (2001). Psicologia Clínica, um novo espetáculo: dimensões éticas e políticas. Psicologia Ciência e Profissão, 21 (4). Acesso em 11 de maio de 2007 de http://pepsic. bvs-psi.org.br/scielo.php?script=sci_arttext\&pid=S14148932001000400009.

Spanoudis, S. (1981). Apresentação: a todos que procuram o próprio caminho. Em M. Heidegger, Todos nós... Ninguém: um enfoque fenomenológico do social (p. 9-22). São Paulo: Moraes.

Tassinari, M. A. (1999). Plantão Psicológico Centrado na Pessoa como Promoção de Saúde no Contexto Escolar. Dissertação de Mestrado, Universidade Federal do Rio de Janeiro. Acesso em 10 de fevereiro de 2007 do: http://www.encontroacp.psc.br/teses.htm.
Yamamoto, O. H., Oliveira, I. F., \& Campos, H. R. (2002). Demandas Sociais e formação profissional em Psicologia. Revista do Departamento de Psicologia da UFF, 14 (1), 75-86.

Melina Séfora Souza Rebouças - Psicóloga, Especialista em Psicologia Clínica na Abordagem Fenomenológico-Existencial e Mestranda em Psicologia pela Universidade Federal do Rio Grande do Norte (UFRN).

E-mail:melina_sefora@yahoo.com.br.

Elza Dutra - Professora Doutora do Programa de Pós-Graduação em Psicologia da Universidade Federal do Rio Grande do Norte (UFRN). Endereço Institucional: Universidade Federal do Rio Grande do Norte, Centro de Ciências Humanas Letras e Artes, Departamento de Psicologia. Campus Universitário, Lagoa Nova, s/n. CEP 59.075-970 - Natal, RN, Brasil. E-mail: dutra.e@digi.com.br

Recebido em 25.11.09 Aceito em 12.03 .10 